\title{
Article
}

\section{Agile manufacturing practices: the role of big data and business analytics with multiple case studies}

Gunasekaran, Angappa, Yusuf, Yahaya, Adeleye, Ezekiel O. and Papadopoulos, Thanos

Available at http://clok.uclan.ac.uk/20561/

Gunasekaran, Angappa, Yusuf, Yahaya ORCID: 0000-0001-6045-3245, Adeleye, Ezekiel O. and Papadopoulos, Thanos (2017) Agile manufacturing practices: the role of big data and business analytics with multiple case studies. International Journal of Production Research, 56 (1-2). pp. 385-397. ISSN 0020-7543

It is advisable to refer to the publisher's version if you intend to cite from the work. http://dx.doi.org/10.1080/00207543.2017.1395488

For more information about UCLan's research in this area go to http://www.uclan.ac.uk/researchgroups/ and search for <name of research Group>.

For information about Research generally at UCLan please go to http://www.uclan.ac.uk/research/

All outputs in CLoK are protected by Intellectual Property Rights law, including Copyright law. Copyright, IPR and Moral Rights for the works on this site are retained by the individual authors and/or other copyright owners. Terms and conditions for use of this material are defined in the policies page.

\section{CLoK}

Central Lancashire online Knowledge www.clok.uclan.ac.uk

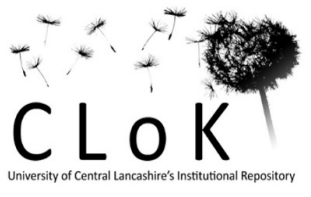




\title{
Agile Manufacturing Practices: The Role of Big Data and Business Analytics with Multiple Case Studies
}

\author{
Angappa Gunasekaran ${ }^{1 *}$, Yahaya Y. Yusuf ${ }^{2}$, Ezekiel O. Adeleye ${ }^{3}$, and Thanos Papadopoulos ${ }^{4}$ \\ ${ }^{1}$ School of Business and Public Administration, California State University - Bakersfield, 9001 \\ Stockdale Highway, Bakersfield, California 93311-1022, USA \\ Tel: (661) 654-2184; Fax: (661) 654-2207; E-mail: agunasekaran@,csub.edu \\ ${ }^{*}$ Corresponding Author \\ ${ }^{2}$ School of Management, University of Central Lancashire, Preston PR1 2HE, U.K. \\ ${ }^{3}$ Department of Business Administration, Elizade University, P.M.B. 002, Ilara-Mokin, Ondo State, \\ Nigeria \\ ${ }^{4}$ Kent Business School, University of Kent, Sail \& Colour Loft, The Historic Dockyard, Chatham, \\ U.K.
}

\begin{abstract}
The purpose of this study was to examine the role of big data and business analytics (BDBA) in agile manufacturing practices. Literature has discussed the benefits and challenges related to the deployment of big data within operations and supply chains, but there has not been a study of the facilitating roles of BDBA in achieving an enhanced level of agile manufacturing practices. As a response to this gap, and drawing upon multiple qualitative case studies undertaken among four U.K. organizations, we present and validate a framework for the role of BDBA within agile manufacturing. The findings show that market turbulence has negative universal effects and that agile manufacturing enablers are being progressively deployed and aided by BDBA to yield better competitive and business performance objectives. Further, the level of intervention was found to differ across companies depending on the extent of deployment of BDBA, which accounts for variations in outcomes.
\end{abstract}

Keywords: big data and business analytics, agile manufacturing, enablers, competitive advantage, performance 


\section{Introduction}

Over the last decades, efforts to improve manufacturing were marked by the emergence of several generic strategies such as total quality management (TQM); just in time (JIT); and computerized planning systems, including materials requirements planning (MRP I), manufacturing resource planning (MRP II), and enterprise resource planning (ERP) (Karlsson, 1996; Nandhakumar, Ghobadian, and O’Regan, 2011). However, market turbulence, characterized by big, sudden successes and failures, continues to threaten success, and the deployment of strategies aiming at manufacturing fewer products (Lampel and Mintzberg, 1996; Lewis, 2000; Power, Sohal, and Rahman, 2001; Jadhav, Mantha, and Rane, 2014) or process-oriented improvement techniques such as lean production (Sheridan, 1998; Bartezzaghi, 1999; Nandhakumar, Ghobadian, and O’Regan, 2011) no longer guarantee profits and market share.

To address this issue, several conceptual methods and techniques, including mass customization, supply chain networking, manufacturing automation, employee empowerment, and concurrent engineering, have been proposed and developed (Gunasekaran, 1998; Gunasekaran, 1999; Sharifi and Zhang, 2001; Carvalho, Azevedo, and Cruz-Machado, 2012). As businesses continued to experience sudden rises and falls, agile manufacturing came into the limelight in the 1990s as a way out of the problem. It was articulated as the enabler of the timely delivery of innovative solutions ahead of the competition through enterprise-wide integration of a wide range of resource capabilities (Bodine, 1998; Gunasekaran, 1998; Sharifi and Zhang, 2001).

Agile manufacturing stresses simultaneous excellence on a wider range of competitive metrics, especially being first to market with leading-edge solutions that surpass customer expectations and derail competitors' plans, delivered at the cost of mass production (Fitzgerald, 1995; Gunasekaran, 1998; Adeleye and Yusuf, 2006; Nandhakumar, Ghobadian, and O’Regan, 2011). Agile manufacturing helps companies be competitive and thrive in environments where change is continuous and unanticipated (Sarkis, 2001; Cao and Dowlatshahi, 2006). Literature has highlighted the role of information technology as an enabler in agile manufacturing (e.g., Gunasekaran, 1999; Yusuf et al., 1999; Cao and Dowlatshahi, 2006; Dubey and Gunasekaran, 2015). In a recent study, Dubey and Gunasekaran (2015) suggest that agile manufacturing is inextricably related to the technologies that can share information effectively and efficiently, enabling organizations to improve dynamic sensing and speed (Elkins et al., 2004). Hence, technologies and information-sharing in particular are crucial 
for the achievement of agile manufacturing. With the advent of digital technologies, big data and business analytics (BDBA) came to the foreground as an important capability that enables companies to create value from an increasingly massive (and unstructured) amount of data, thereby gaining competitive advantage (Chen et al., 2012). BDBA, according to Wang et al. (2016), comprises two elements: (i) big data and (ii) business analytics. The former term refers to the gathering and processing of data that has the qualities of velocity, variety, and volume. The latter term has to do with applying the appropriate methods and techniques to enable decision-making. Within logistics and supply chain management, a number of recent studies have demonstrated the benefits of big data (e.g., Wamba et al., 2015; Wang et al., 2016; Hoffman, 2017; Kim and Ahn, 2017; Papadopoulos et al., 2017; Zhong et al., 2017) across different contexts, e.g. manufacturing (Jain et al., 2017), health sector (Wu et al., 2015) and semiconductors (Wang and Zhang, 2016). Others have suggested a positive link to firm performance (Ji-Fan Ren et al., 2017) and to better decision-making (Tan et al., 2017). This new emergent work suggests that BDBA plays a major role in the agility of an organization. It does so by providing timely and more accurate information about product demand (demand planning) and by quickly designing and developing an integrated supply chain network, product and process, and collaboration among partnering firms. Moreover, BDBA helps in inventory control, transportation, scheduling, and quality control at the operational level by having more accurate and timely information for making correct decisions in support of agility.

However, very little has been achieved in understanding the role of BDBA in the establishment of agile practices (Vázquez-Bustelo, Avella, and Fernández, 2007; Zhang, 2011; Leite and Braz, 2016). To this end, the current study addresses the following question: What is the role of BDBA in achieving agile manufacturing? A multiple qualitative case study strategy was followed, which included structured interviews with executives in four organizations. We (i) clarify the definition and relationship between agile manufacturing and BDBA; (ii) propose a conceptual framework that extrapolates particular factors necessary to this relationship; and (iii) discuss this framework through qualitative data.

The organization of the paper is as follows: The next section discusses the literature on agile manufacturing and the role of big data, and section 3 the methodology. Section 4 describes our findings, and section 5 compares our findings to the literature. Section 6 concludes the paper and provides future research avenues. 


\section{The concept of agile manufacturing}

Strategic manufacturing approaches such as mass production, lean production, time-based competition, and mass customization have evolved since the 1960s, leading up to agile manufacturing post-2000 as an emergent model for coping with sporadic and turbulent change. The pressures compel an extension of the competitive bases beyond the basic objectives of cost and quality to include technology leadership and intense customization. In this regard, the need arises to unfold the manufacturing system in order to marshal new enabling competencies across networks of enterprises, master change, and deliver new solutions on a sustainable basis (Ward, McCreery, Ritzman, and Sharman, 1998; Bhattacharya, 1996; Mason-Jones et. al., 2000; Oyedijo, 2012; Leite and Braz, 2016). Agility, therefore, is the ability to correctly envision change, seamlessly reconfigure operations, and offer transparent added value to products and customers (Zhang, 2011; Dubey and Gunasekaran, 2015). To this end, researchers have discussed several requisite principles, enablers, and frameworks, but have highlighted the role of mass customization (Booth and Hammer, 1995; Dubey and Gunasekaran, 2015).

Mass customization has been articulated as tracking, devising, and adding value to current products and customers, offering a wide range of product options in parallel and targeting them to different niche markets and customers (Fitzgerald, 1995; Leite and Braz, 2016). This is quite unlike mass production, which tenders a few standard products for everyone, and lean production, which offers families of related products in rapid succession (Adeleye, Yusuf, and Sivayoganathan, 2000; Power et. al., 2001). For sustainable mass customization, agility means transparent response to transitions in customer values (Feitzinger and Lee, 1997; Thomas, 2014).

The intensity of mass customization would differ across product markets, and a continuum—ranging from cosmetic to transparent customization — has been identified, the latter being the goal of agile manufacturing (Lampel and Mintzberg, 1996; Fisher, 1997; Leite and Braz, 2016). Nevertheless, the required resource capabilities are beyond single companies but within the reach of networked companies operating as virtual resource coalitions (Browne, Sachett, and Wortmann, 1995). In addition, the knowledge of the intensity of market turbulence and the range and depth of deployable agile manufacturing enablers applicable in different contexts are hard to pin down (Vinodh, Devadasan, and Rajanayagam, 2008; Zhang, 2011). 


\subsection{A framework for agile manufacturing}

Agile manufacturing hinges on particular drivers, enablers, and outcomes (Yusuf, Sarhadi, and Gunasekaran, 1999; Vázquez-Bustelo et al., 2007; Oyedijo, 2012; Dubey and Gunasekaran, 2015). Figure 1 is based on this literature and presents a theoretical framework of the expected relationship among market turbulence, enablers of agile manufacturing, competitive objectives, and performance outcomes, which are central to agile manufacturing. We propose that BDBA provides the basis for identifying and deploying agile manufacturing enablers (Bartezzaghi, 1999; Mason-Jones, Naylor, and Towill, 2000) toward the positive attainment of competitive objectives and business performance outcomes (Gunasekaran, 1999; Sharifi and Zhang, 2001; Zhang, 2011), subject to market turbulence.

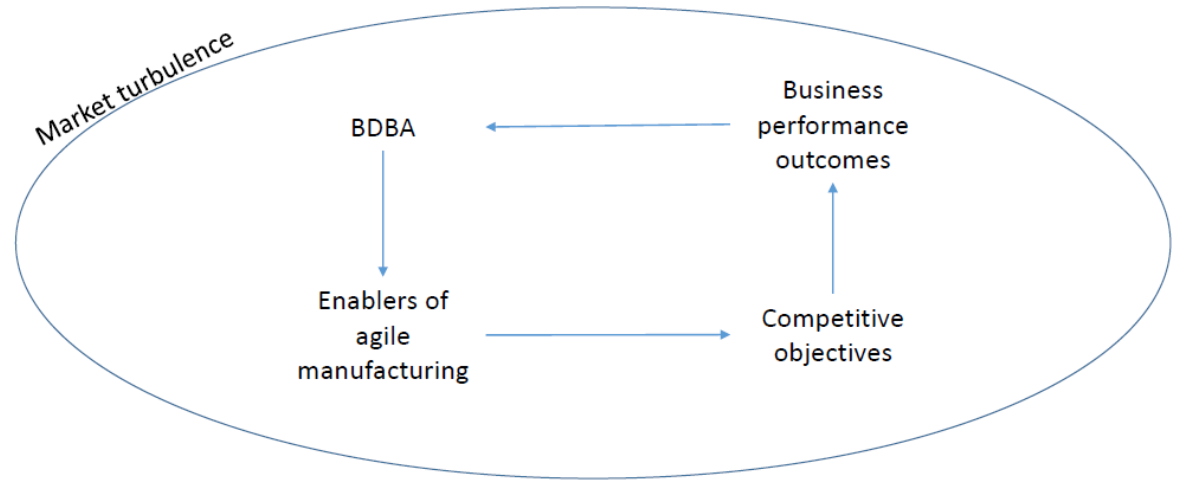

Figure 1. Theoretical framework for agile manufacturing

\subsubsection{Big data and business analytics}

The role of BDBA within business has been highlighted, especially when considering its elements that is, volume, velocity, and variety (Zhou et al., 2014; Duan and Xong, 2015), or, according to Wamba et al. (2015), volume, velocity, variety, veracity, and value. Volume has to do with the amount of generated data, whereas velocity refers to the rate at which data is generated. Variety is a characteristic describing the different formats of data, and veracity refers to the unpredictability with regards to reliable predictions, while value is the benefits to be accrued through the use of big data. Literature has outlined the benefits of BDBA (Wamba et al., 2015; Akter et al., 2016; Dubey et al., 2016; Wang et al., 2016b; Amankwah-Amoah, 2016; Matthias et al., 2017), stating that the predictive power of big data (through business analytics) is about using the power of statistics to forecast future events based on what has occurred in the past. Tools include, for instance, regression modeling, 
decision trees, Bayesian statistics, neural networks, Support Vector Machine (SVM), and nearest neighbor algorithms (Oztekin, 2017). Literature has discussed BDBA as a capability that leads to better performance and relies on bundling strategic resources (Akter et al., 2016; Wang et al., 2016; Wamba et al., 2017). In a recent study, Dubey et al. (forthcoming) discussed the impact of BDBA on improving social and environmental sustainability, while others have explored the impact of BDBA on performance and related contextual factors (Akter et al., 2016; Gupta and George, 2016; Wamba et al., 2017; Gunasekaran et al., 2017). However, the impact of BDBA on agile manufacturing has not been explicitly studied in the literature, giving us the impetus for this paper.

\subsubsection{Enablers of agile manufacturing}

The enablers of agile manufacturing, the tools and resource competencies defend competitive objectives against the perturbing influence of market turbulence (Almahamid et al., 2010; Oyedijo, 2012; Zhang et al., 2017). To this end, literature has focused, inter alia, on transparent customization, enterprise-wide supply chain networking, total employee empowerment, intelligent automation, and technology integration (Gunasekaran, 1999; Yusuf and Gunasekaran, 2002) as enablers of agile manufacturing. Oyedijo (2012) identified and justified four enablers: organization, people, technology, and planning. Likewise, Dubey and Gunasekaran (2015) validated six constructs: technologies, employee empowerment, customer focus, supplier relationships, a flexible manufacturing system, and organizational culture.

Transparent customization as an agility enabler strives for significant added value, in contrast to cosmetic customization, with little or no significant enhancements, or lean product development, which could add more to costs than to revenue (Fisher, 1997; Thomas, 2014). In the pharmaceuticals sector, many manufacturers now supply single-dose packages for midday administration, soluble tablets, and blister packs for vulnerable users and nursing homes. In food processing, as well, products now come in a bewildering variety of sizes, packs, and variations: diet, low sodium, decaffeinated, kid's size, and so forth. A wider range of options delights customers and creates the potential for higher sales, market share, and profits. What is important, however, is the uniqueness or transparency of innovation contained in each product option.

In support of this strategy, manufacturers seek programmable, intelligent automation to enable a wider range of machining and assembly operations without the changeover costs of flexible automation. 
This is in addition to efforts to leverage knowledge and compress cycle times by building stakes in agile supply chains for opportunistic response while also investing in the total empowerment of employees. Apart from a few studies on the partial impacts of some specific agile manufacturing enablers, their joint or interaction effects when deployed, relative to the extent of market turbulence, were yet to be fully investigated (Zhang, 2011; Oyedijo, 2012). Yet quantification and total agile design are crucial to sustainable deployment in practice (Vinodh et al., 2008; Vinodh, Sundararaj, and Devadasan, 2009; Jadhav et al., 2014; Routroy, Potdar, and Shankar, 2015).

\subsubsection{Competitive objectives}

Competitive objectives consist of the set of values delivered to customers, seven of which are widely discussed (Vokurka and Fliedner, 1997; Ward et. al., 1998; Yusuf et al., 1999; Ling, 2000; Islam and Karim, 2011). They are low cost, quality, speed, dependability, product customization, volume flexibility, and leadership in new technology products. If the agility enablers are correctly identified and deployed, it is possible to minimize trade-offs, score simultaneously on them, and compete on all fronts (New, 1992; Ward et. al., 1998; Silveira and Slack, 2001). This ability is invaluable in shielding the business from the perturbing influence of market turbulence (Gunasekaran, 1998; Ling, 2000; Sharifi and Zhang, 2001; Almahamid et al., 2010).

\subsubsection{Business performance}

Business performance is the barometer for measuring business success-both financial and nonfinancial. The most popular measures are sales turnover, net profit, market share, proportion of sales turnover from new products, customer loyalty based on repeat orders, and performance relative to competitors (Ling, 2000; Islam and Karim, 2011).

Competitive objectives impact business performance (Bodine, 1998; Ling, 2000). Put simply, any cost savings in space or material utilization benefits the end customer through a lower price and translates into higher sales and profit. Likewise, enhanced quality (competitive objective) motivates customer confidence, hence, higher sales, market share, and profit.

Business performance is connected back to BDBA. This may occur, for instance, when financial and non-financial outcomes as well as sustainability in terms of consistent innovation and growth that respects resource use and environmental stewardship need to be used for BDBA (Ocampo and 
Ocampo, 2015). Therefore, we propose that BDBA is the originating point for our theoretical framework.

\subsubsection{Market turbulence}

Market turbulence is generally perceived as the driving force for agile manufacturing. Four sources of market turbulence have been widely discussed-global competition, new technology, customized solutions, and new product introduction (Booth and Hammer, 1995; Brown et al, 1995; Vokurka and Fliedner, 1998; Dubey and Gunasekaran, 2015). However, the intensity of market turbulence differs across companies, hence, the level of required agility will be context-specific (Zhang, 2011).

\subsubsection{Research objectives}

There is a paucity of literature discussing the role of BDBA in achieving agile manufacturing. In particular, the literature has not discussed the effect of BDBA on the enablers of agile manufacturing that lead to competitiveness and performance. Therefore, our suggested framework lacks prior empirical validation, while the link between BDBA and various agility enablers remain poorly understood (Sarkis, 2001; Vinodh et al., 2009; Zhang, 2011). We address this gap in the literature using a qualitative multiple case study strategy, which is presented in the following sections.

\section{Methodology}

In-depth data were collected from four manufacturing companies in the U.K. The aim was to conduct more in-depth and context-specific study of BDBA, agile manufacturing practices, and the associated competitive and business performance outcomes (Eisenhardt, 1989; Collins and Cordon, 1997).

The case study as a research strategy was selected because of its ability to study a phenomenon in real conditions, and especially as the phenomenon and its context (turbulent environment) was not clearly evident (Yin, 1981; Ketokivi and Choi, 2014). Over the years, there has been a significant increase in the use of case study, especially for theory building (Ketokivi and Choi, 2014). Pagell and Wu (2009) have illustrated the importance of the case study method in their seminal paper where they discussed how to build a more complete theory of sustainable supply chain management. To avoid any bias, this research paid attention to the context and selection of participants, data collection, and analysis (Rymaszewska et al., 2017). All the selected cases are in the manufacturing sector and have been undergoing a period of shifting and adopting BDBA. However, they were also selected on the basis 
of their different stages of involvement in BDBA for agile manufacturing and diverse environments (contexts) in terms of their turbulence. Thus, their selection would help understand the role of BDBA within agile manufacturing.

Initial contacts were made via a letter addressed to the CEOs. The letter explained the purpose of the study and promised useful feedback on the results as well as confidentiality (Nachmias and Nachmias, 1992). Some case study materials were thereafter mailed to the appointed facilitators and were returned to the researchers ahead of the plant visits, which were conducted by a team of two researchers. Activities during the visits started with structured interviews, a guided walk through the plants, observations, and the collection of available published materials (Vázquez-Bustelo and Avella, 2006). In two of the four companies, the main interviews were held with the CEOs, while they involved two senior managers in manufacturing in the two other companies.

The main tool consisted of two structured interview documents. The first structured interview document consisted of eleven questions directed at the head of manufacturing, while the second contained six questions for two other departmental heads outside the manufacturing function. The first focused on agile manufacturing initiatives, while the second investigated work process changes in other departments. Both documents included questions on how BDBA has enabled them to start a journey toward agile manufacturing and transformation.

The responses of the interviewees were tape recorded and transcribed verbatim. The analysis followed the thematic analysis method by Miles and Huberman (2003). Due to the nature of the study, which included a relatively small number of interviews, and following Rymaszewska et al. (2017), the coding was performed manually on the hard copy printouts of the interview transcripts (Saldaña, 2015). This way of coding was guided by our framework (informed by the literature review) and by our aim to explore the relationship of BDBA and agile manufacturing. The coding was conducted by the third author, while the other authors (first, second, and fourth) did additional coding, confirming and ensuring the reliability of the codes. In cases of minor disagreements, the codes were further discussed until agreement was reached. In this vein, reliability of the analysis as well as validity (checking interview data with reports by the companies) was secured. 


\subsection{Company profiles}

Table 1 presents the profile report of the companies studied. Company A was founded in 1961 as an edible salt packaging business, but has extended to a range of edible and non-edible products. Twentyfive percent of current business is in packaging salt for dishwater. The company has three factories, but only one was visited. The site visited has annual sales of over $f^{11}$ million and 130 workers.

Company B is a leading manufacturer of refrigerated cooling systems for vegetable crops storage. Its products were designed for long-term and bulk storage of potatoes, onions and vegetables to keep quality close to harvest condition. The company has two sites but only one was visited. The site studied had fifty employees and an annual turnover of over 45 million pounds.

Table 1. Brief profile of companies studied

\begin{tabular}{|l|l|l|l|l|}
\hline Plant visited & Founded & Sales & Workers & Major business \\
\hline A & 1961 & $\begin{array}{l}\text { Over f11 } \\
\text { million }\end{array}$ & 130 & $\begin{array}{l}\text { Packaging food / non-food } \\
\text { products }\end{array}$ \\
\hline B & - & $f^{45}$ million & 50 & $\begin{array}{l}\text { Refrigerated cooling system for } \\
\text { bulk storage of potatoes / } \\
\text { vegetables liquid }\end{array}$ \\
\hline C & - & $£, 320$ million & 550 & $\begin{array}{l}\text { Tablet and and } \\
\text { pharmaceuticals }\end{array}$ \\
\hline D & 1991 & $f^{81 \text { million }}$ & 230 & $\begin{array}{l}\text { Manufacture of medical and } \\
\text { electro-surgical equipment }\end{array}$ \\
\hline
\end{tabular}

Company $\mathrm{C}$ is a chemical and pharmaceutical products manufacturer, trading in more than 130 countries, with staff strength of over 57,000 and sales turnover above $f, 13$ billion. The site visited has an average annual sales turnover of about $£ 320$ million and a workforce of 550 . The plant makes fifteen basic products, mainly tablets, reconstituted granules, capsules, and chemicals in about fifty different formulations. Seventy-five percent of turnover was exported.

Company D manufactures specialist medical utilities, such as electro-surgical equipment, operating tables, autoclaves, and pumps. The products had over 180 models, all manufactured to stock. Operations were in low volumes and consisted of the manual assembly of hundreds of components into life equipment used by hospitals and surgical laboratories. The leading model was launched in 1991, and it currently accounts for 10 percent of sales. Annual sales turnover is about $f^{8} 81$ million 
pounds, and employee strength is 230. Major customers are NHS Trusts and independent distributors around the world.

\section{Data analysis}

The section presents the results of the study. The analysis is structured around the role of BDBA within agile manufacturing and, in particular, its influence on agile manufacturing enablers, competitive objectives, and performance outcomes, considering market turbulence (Table 2).

\subsection{Implementation of the agility enablers}

Following the literature, the study looked for agility enablers, including system design, supply chains, manufacturing technology, and organizational empowerment. This section presents case-by-case analysis and a summary of the level of adoption of the agility enablers in Table 2.

Table 2. Summary of the level of deployment of the agile manufacturing enablers

\begin{tabular}{|l|l|l|l|l|}
\hline \multirow{2}{*}{ Agile manufacturing enablers } & \multicolumn{4}{|c|}{ Companies } \\
\cline { 2 - 5 } & \multicolumn{1}{|c|}{ A } & \multicolumn{1}{|c|}{ B } & \multicolumn{1}{c|}{ C } \\
\hline 1. Intelligent automation & Modest & High & High & Modest \\
\hline 2. Total empowerment of workers & Low & High & Very high & Modest \\
\hline 3. Agile supply chains & Modest & High & Excellent & Low \\
\hline 4. Mass customization & Modest & Very high & Very high & Modest \\
\hline 5. Operational flexibility & Low & High & Very high & Modest \\
\hline
\end{tabular}

\subsubsection{Company A}

The factory in Company A consists of simple machines arranged sequentially into workstations. Equipment changeover times and costs were relatively high, and in effect, low volume production of customized labels was relatively expensive. Manufacturing technologies were not elaborately applied, but the CEO claims that the principles underlying their use were understood and applied. The CEO claimed, "There is nothing really high-tech in all that we do."

Supply chain practices are defined by open competitive tendering and punitive rationalization underpinned by the "ability to supply specifications and cost." Employee empowerment was weak, as 
top management controls routine processes. The CEO concurred that "Top managers are responsible for everything."

The foregoing discussion shows that Company A has been relatively weak in deploying BDBA for the agile manufacturing enablers. Specifically, enhancements to product features and data used focused on size and shape (cosmetic customization) rather than technical functions (transparent customization).

\subsubsection{Company B}

The factory in Company B, the refrigerated cooling solutions provider, consists mainly of small-scale and general-purpose machines, aside from a semi-automatic band saw that was bought recently. Separate but interdependent workbenches engage in cutting, shaping, filing, painting, imprinting, wiring, assembly, and testing, each of which is operated by highly skilled engineers and technicians. To enhance the efficiency of stocks and parts costing and control as well as job tracking and scheduling, a proprietary production management system, Job Boss, was purchased recently.

On worker empowerment, the company stressed team spirit among employees, scoring highly on the quantitative measures of the power of team members relative to team leaders, on-the-job training, free flow of knowledge among workers, individual responsibility for job completion and quality, implementation of suggestions, and responsibility-based wages. A weekly production control meeting that specifies the rolling production sequence over the next two to three weeks was the strongest tool for coordination and communication.

The company nurtured customer and supplier confidence and rapport through several means, such as emails, a quarterly newsletter, and the website. These were in addition to some advertising and editorials in specialist media and exhibitions in national and international events. The company opined, however, that reaching out to suppliers and sales agents was much easier than reaching out to end users and customers, and they were harnessing BDBA to this purpose: "We build a stronger relationship with our suppliers as a means of shortening lead times, and improving delivery reliability and certainty." 
On mass customization, the company had started customizing its own component labels as a means of enhancing value added. Furthermore, stock control, parts costing, production planning, dispatching, and invoicing were being reorganized in support of the shift from a project-based system to a more flexible batch processing system. As such, the processes of metal cutting, painting, and wiring were to be automated soon. According to the CEO, automation would evolve in the light of new emphasis on fully packaged, factory-built systems combining refrigerated cooling with ambient ventilation and air mixing. The overriding determinant will be "Time saving and payback in relation to volume and employees' costs."

\subsubsection{Company C}

In Company $\mathrm{C}$, the factory consists of several product line families of related tablets and reconstituted granules, integrated into flow lines connected by pipes for moving in-process materials. The range of skills within each line was high.

Manufacturing automation is significant:

a. The use of key-on, key-off computerized control panels to monitor quality, safety, and tablet force information every two hours.

b. The use of a camera system in the packaging lines, which detected and rejected blisters and other packages containing missing and under-counted tablets.

c. Examination of in-process tablet samples every fifteen minutes.

The company emphasized demand planning and control, especially through the use of BDBA, and in particular:

a. Dedicated staffs in charge of demand management for specific products,

b. The SAS BPCS software bought last quarter but still being modified,

c. The use of a computerized Conformance Measures Status Chart,

d. A modest amount of contingency stocks in anticipation of winter disasters, and

e. A large stock of materials as well as pre-printed cartons and user instructions.

Employee empowerment was total. Operators and technicians were considered the most crucial asset, trained in multiple skills, including BDBA, and motivated for teamwork to handle several support jobs while on the line. There was the evidence of suggestion schemes, reward for project completion, performance-based pay, ownership through shareholding, and career stability. 
As well, supply chain practices featured electronic enquiries, open competitive tendering, long-term contracts, and long delivery lead times, but limited collaboration in design and manufacture. Approved supplier status had been introduced as well as several customer-focused initiatives, including:

a. "Establishment of a new Communication department, which is to ensure that the company is more closely aligned with the changing NHS."

b. "Creation of two special units for sales and marketing in new franchises."

c. Appointment of an administrator to manage demand for named patent supplies of a recently launched new chemical entity in the field of HIV.

Direct relationship with competitors is now being compelled by "Global initiative to reduce cost in the purchase of materials and engage in collaborative research."

On mass customization, the company is committed to paced introduction of advanced formulations ahead of competitors and protecting them with patents. Packages and blisters have been customized for patient convenience rather than attraction, even as some generic and cheaper formulations are now available for lower-income nations. This is in addition to emphasis on routing, operational, and capacity flexibility within the limits of regulatory controls such as total batch segregation. An informant stated, "We use job sequencing to minimize machine changeovers, which took between twenty-four to thirty hours, but have been replaced by complete off-line re-tooling."

\subsubsection{Company D}

The factory of Company D, the specialist medical equipment manufacturer, is operated as a job shop and is structured into two major units: the operating tables unit and the electro-surgical assembly unit. They both run as low-volume batch processes, with operations terminating in an off-line assembly and testing unit. Within each unit, the company also repairs and services products already sold to customers.

The company scored relatively low on process automation, because "the products are complex and cannot easily be automated to a high degree." However, further questioning revealed that certain processes would be automated appreciably after current efforts to simplify product design and assembly through "kit component parts." In addition, automated storage and picking systems as well as in-house automated production of printed circuit boards (PCB) were being evaluated. 
Employees were highly educated and skilled in BDBA, but team disposition was low due to a compartmentalized structure and the putting of round pegs in square holes. For instance, an accountant was said to have headed manufacturing until recently. In addition, material stores were decentralized on a product basis and poorly organized and documented, while overall authority for stores rested in the head of personnel. The interviews revealed mutual suspicion, lack of trust, limited functional integration, a culture of "us" and "them," and emails being used as an instrument of "trench warfare."

Supply chain collaboration with suppliers, customers, and competitors was miserable, and therefore any mutual BDBA attempts were futile. The company has seven major competitors in the U.K. and several others in Europe, but no direct relationship of any form. The same applies to major customers who were independent distributors around the world and NHS Trusts in the U.K. Nevertheless, NHS databases were remotely accessed for contracts available and bid specifications. On the NHS as the most valued customer, a principal informant stated that "bureaucracy does not allow for personal relationships."

Supplier numbers are often rationalized and new agreements entered into, in line with new product development initiatives. A Direct Alliance Scheme under which quality assurance personnel will visit and monitor implementation of specifications in major supplier companies was being planned.

The following extracts from interview reports reveal several supply chain problems:

- "Recently, two major projects ran out of control, partly due to software design problems with sub-contractors."

- "Emphasis on a better quality of suppliers limits options and leads to a greater reliance on Grade 1 core suppliers, who now demand better and closer support.”

The preceding report on the degree of implementation of the agile manufacturing enablers shows significant efforts in all the companies to cope with market turbulence and survive rather than perish. However, greater progress was reported for B and C, even as robust plans to implement the agile manufacturing enablers of competitive advantage were reported. To this extent, Hypothesis 2, which proposes that there is no relationship between the intensity of market turbulence and the deployment of agile manufacturing enablers, is not justifiable, and is hereby rejected. 


\subsection{The impact of the agile manufacturing enablers}

The case studies collected data on the current attainment and future aspirations on seven competitive objectives. The companies generally returned high levels on some, while future aspirations for all were high (Table 3).

Table 3. Companies' current attainments and future aspirations

\begin{tabular}{|c|c|c|c|c|}
\hline & Companies' attainment & & Companis & aspirations \\
\hline $\begin{array}{l}\text { COMPETITIVE } \\
\text { OBJECTIVES }\end{array}$ & Low end & High end & Low end & High end \\
\hline 1. Lower production costs & $A, D$ & $\mathrm{~B}, \mathrm{C}$ & & $\mathrm{B}, \mathrm{C}, \mathrm{D}$ \\
\hline $\begin{array}{l}\text { 2. First to market with new } \\
\text { products }\end{array}$ & A, B & & & $\mathrm{A}, \mathrm{B}, \mathrm{C}, \mathrm{D}$ \\
\hline $\begin{array}{l}\text { 3. Leading technology } \\
\text { products }\end{array}$ & & A, C & & A, B, C \\
\hline $\begin{array}{l}\text { 4. Better after sales/ tech } \\
\text { support }\end{array}$ & $\mathrm{D}$ & A, C & & A, C, D \\
\hline 5. Superior quality of design & $\mathrm{D}$ & B & & $\mathrm{B}, \mathrm{C}, \mathrm{D}$ \\
\hline $\begin{array}{l}\text { 6. Higher quality } \\
\text { conformance }\end{array}$ & & $\mathrm{B}, \mathrm{C}$ & & $\mathrm{B}, \mathrm{C}, \mathrm{D}$ \\
\hline $\begin{array}{l}\text { 7. Swift response to } \\
\text { demand surges }\end{array}$ & & $\mathrm{C}$ & & A, C, D \\
\hline
\end{tabular}

Also, Table 4 presents the degree of market turbulence (low vs. high) for each of the companies (and, hence, case studies).

Table 4: Degree of market turbulence (low vs. high) for each of the companies

\begin{tabular}{|l|c|c|}
\hline \multirow{2}{*}{ Company } & \multicolumn{2}{|l|}{ Degree of market turbulence } \\
\cline { 2 - 3 } & Low & \\
\hline A & $\sqrt{ }$ & \\
\hline B & $\sqrt{ }$ & $\sqrt{ }$ \\
\hline C & & $\sqrt{ }$ \\
\hline D & & \\
\hline
\end{tabular}

Focusing only on the two extremes of low-end and high-end attainment, all four companies were identified with high-end attainments on a range of competitive objectives.

The competitive objectives and performance were realized after the implementation of enablers. Table 5 reports the direction of change in performance outcomes after the adoption of the agile manufacturing enablers to achieve competitive objectives. Companies B and $\mathrm{C}$ that returned 
high-end current attainment as well as high-end future aspirations on a wider range of competitive objectives in Table 3 are shown in Table 4 to have experienced a sharp increase in the last five years on several business performance outcomes. This differs sharply from the evidence facing A and D.

Table 5. Attainment on business performance outcomes

\begin{tabular}{lcc}
\hline Direction of change in the last five years & Sharp decrease & Sharp increase \\
\hline Sales turnover & D & B \\
Profit after tax & A, D & B \\
Market share & D & \\
Customer loyalty (repeat orders) & D & B \\
Value-added to throughput & & B, C \\
Utilisation of fixed assets e.g. machines & D & C \\
Returns to company owners & & B \\
Process and product innovation & & C \\
Growth and expansion prospects & B C \\
Support to community or environment & B & \\
Performance relative to competitors & D & \\
\hline
\end{tabular}

Some other case study reports on Company B show that the implementation of agile initiatives has positively impacted reliability and flexibility, hence, the value added to throughput, repeat orders, sales turnover, net profit, and return to shareholders has been positive in the last five years. In Company C, as well, there is more convincing evidence of swift responses to large order volumes during epidemics, scientific breakthroughs, and regulatory controls through agile manufacturing initiatives. Consequently, sales turnover, net profit, market share, value added to throughput, asset utilization, and expansion prospects have been positive over the last five years. One principal informant in Company $\mathrm{C}$ opined, "Fortunately, on average, we have been on the winning side, not on the losing side."

\section{Discussion}

Successful deployment of agile manufacturing requires acknowledging the role of BDBA in harmonizing and applying the whole range of agility enablers. Our previous discussion illustrates that Companies B and C implemented a wider range of initiatives. Responses to the questions on agile initiatives toward enhanced operational flexibility show that Companies B and C are more consistent over the whole range.

- Contingency inventories [Companies A, B, C, and D]. 
- Customer site and in-plant assembly in parallel [Company B].

- JIT purchasing and scheduling [Companies B and C].

- Demand planning and forecasting [Companies B and C].

- Complete off-line retooling [Company C].

- Flexible supply chain [Company C].

- Dedicated communication and marketing [Company C].

- Modular kit parts [Company D].

- Strategic purchasing [Company D].

Anything less than integrative and harmonious deployment would not achieve significant results (Yusuf and Adeleye, 2003; Vázquez-Bustelo et. al., 2007; Vinodh et. al., 2009; Oyedijo, 2012). This accounted for the relatively poor results reported for Companies A and D, especially on operational and volume flexibility, which is the agile manufacturing conundrum (Upton, 1995; Yusuf, Adeleye, and Sivayoganathan, 2003; Thomas, 2014). The study therefore advances manufacturing research in that it illustrates that more integrative deployment of BDBA leads to agile manufacturing enablers and greater competitive and business performance outcomes.

Deriving from the foregoing findings, the deployment of BDBA to agile manufacturing should be underpinned by integration of the appropriate range of enablers. The starting point is to enhance the role of BDBA for the enablers of agile manufacturing. Next is the determination of the impact of BDBA on competitive factors and performance. The role of BDBA needs to be grasped by understanding the role of the market turbulence facing the specific company or industrial sector as the basis for understanding whether agile manufacturing is feasible. Before eventual deployment, it is important to compute the interaction index of the agile manufacturing enablers, so that harmony and synergy can be ensured. Therefore, another contribution of this study towards the advancement of manufacturing research is that it highlights that quantification (Vinodh et al., 2008; Routroy et al., 2015) and total agile design (Vinodh et al., 2009) would need to be considered (Jadhav et al., 2014) for increased agility and performance.

From a theoretical point of view, this study contributes to the literature on the role of BDBA for agile manufacturing (Vázquez-Bustelo, Avella, and Fernández, 2007; Zhang, 2011; Leite and Braz, 2016). It underlines the role of big data in achieving agile manufacturing, and competitiveness and performance. In this vein, it adds to the existing literature that states the benefits of BDBA (Wamba et al., 2015; Akter et al., 2016; Dubey et al., 2016; Wang et al., 2016b; Amankwah-Amoah, 2016; 
Matthias et al., 2017), highlighting the capability of BDBA that leads to better performance (Akter et al., 2016; Wang et al., 2016; Wamba et al., 2017) through agile practices. Finally, our study contributes to the further conceptualization of BDBA (Akter et al., 2016; Wamba et al., 2017; Dubey et al., 2018) by looking explicitly at the impact of BDBA on agile manufacturing and its enablers. These studies have looked at benchmarking performance with regards to BDBA (mostly looking at BD as a capability that organizations should have or are working towards attaining) but not with reference to agile, where is the focus of this study. Therefore, our study highlights the role of BDBA on achieving agile performance measures, given a particular type of market turbulence (i.e. Low vs. High). For instance, our study has highlighted the role of BDBA in achieving agility for companies $\mathrm{B}$ and $\mathrm{C}$ related to the performance measures of 'sales turnover', 'profit after tax', and for companies A and C in terms of 'growth and expansion prospects'. Thus, this study highlights the role of BDBA in performance measures but with a reference to market turbulence.

From a managerial perspective, this study highlights the importance that needs to be paid by managers to BDBA in order to become agile and increase their performance. In particular, managers should invest time and resources in developing tools and methods for understanding and enhancing BDBA within their organizations and their supply chains. Furthermore, it is crucial that managers understand the negative role of market turbulence and take appropriate measures in order to be able to predict this through BDBA. Finally, this study highlights to managers particular factors that need to be considered when it comes to BDBA and agile manufacturing, by relating these to business performance outcomes. By adhering to the enablers of manufacturing and harnessing the power of BDBA, managers could enhance agility and performance in their organizations and supply chains.

\section{Conclusion}

This study investigated the role of BDBA within agile manufacturing. A theoretical framework based on the extant literature was developed and further validated using qualitative data (structured interviews) from four companies.

Two of the four companies studied seem to have been more successful in the use of BDBA for agile manufacturing and operational flexibility. The two companies delivered widely on competitive objectives, and, consequently, over the last five years, sharp increases in business performance measures were documented. In contrast, the two other companies were identified as less positive 
toward the agility enablers. They did not deliver widely on competitive objectives, and over the last five years, sharp decreases in business performance measures were documented.

Therefore, BDBA plays a major role in the agility of an organization, helping in gathering and analyzing data on product demand (demand planning), and quickly designing and developing a supply chain network, product and process, and collaboration among partnering firms. BDBA could also be accompanied by future research on: (i) the Internet of Things (IoT), which enables organizations to have an integrated information system in support of supply chain operations and visibility, and, in turn, flexibility and speed of responding to customer or market requirements. Agility requires realtime information in order to act quickly to ensure the whole supply chain's activities are completed, so as to reach the market as quickly as possible and with minimum cost and high-quality products and services. (ii) Industry 4.0 includes the Io'T, cloud computing, and RFID to support automated business processes in manufacturing in order to facilitate real-time information-sharing along the supply chain and, in turn, support the flexibility and speed of an organization to respond to changing market and customer requirements. (iii) Blockchain technologies could offer provenance to big data within supply chains, capturing data regarding products, services, and supply chain tiers in real time, thereby enhancing supply chain agility.

\section{References}

Adeleye, E.O., and Y.Y. Yusuf. 2006. "Towards Agile Manufacturing: Models of Competition and Performance Outcomes.” International Journal of Agile Systems and Management, 1(1): 93.

Adeleye, E.O., Y.Y. Yusuf, and K. Sivayoganathan. 2000. "Leanness, Agility and Manufacturing Performance in the UK." Proceedings of the $4^{\text {th }}$ International Conference on Managing Innovative Manufacturing, Aston Business School, Birmingham, 17-19 July, 19-27.

Akter, S., S.F. Wamba, A. Gunasekaran, R. Dubey, and S.J. Childe. 2016. "How to improve firm performance using big data analytics capability and business strategy alignment?" International Journal of Production Economics, 182: 113-131.

Almahamid, S., A. Awwad, and A.C. McAdams. 2010. "Effects of Organizational Agility and Knowledge Sharing on Competitive Advantage: An Empirical Study in Jordan." International Journal of Management, 27(3): 387-404.

Amankwah-Amoah, J. 2016. "Emerging economies, emerging challenges: Mobilising and capturing value from big data." Technological Forecasting and Social Change, 110: 167-174.

Bartezzaghi, E. 1999. "The evolution of production models: Is a new paradigm emerging?” International Journal of Operations and Production Management, 19(2): 229-250. 
Bhattacharya, A.K. 1996. "Product market, turbulence and time compression: Three dimensions of an integrated approach to manufacturing system design." International Journal of Operations and Production Management, 16(9): 34-37.

Bodine, W.E. 1998. "Making agile assembly profitable.” Manufacturing Engineering 121(4): 60-68.

Booth, C.L, and M.P. Harmer. 1995. "Agility, The Future for Ceramic Manufacturing." Ceramic Engineering Science Proceedings, 16(1): 220-225.

Browne, J., J. Sackett, and J. Wortmann. 1995. "Future Manufacturing Systems - Towards the Extended Enterprise." Computers in Industry, 25: 235-254.

Dowlatshahi S, and Q. Cao. 2006. "The relationships among virtual enterprise, information technology, and business performance in agile manufacturing: an industry perspective." European Journal of Operational Research, 174(2): 835-860.

Carvalho, H., S.G. Azevedo, and V. Cruz-Machado. 2012. "Agile and resilient approaches to supply chain management: influence on performance and competitiveness." Logistics Research, 4(1-2): 49-62.

Collins, R., and C. Cordon. 1997. "Survey methodology issues in manufacturing strategy and practice research." International. Journal of Operations and Production Management, 17(7): 697-706.

Dubey, R., A. Gunasekaran, S. Childe, T. Papadopoulos, Z. Luo, S.F. Wamba, and D. Roubaud (In Press). "Can Big Data and Predictive Analytics Improve Social and Environmental Sustainability?" Technological Forecasting and Social Change. Available from: http://www.sciencedirect.com/science/article/pii/S0040162517305668, $\quad$ DOI: https://doi.org/10.1016/.techfore.2017.06.020

Duan, L., and Y. Xiong. 2015. Big data analytics and business analytics." Journal of Management Analytics, 2(1): 1-21.

Dubey, R., A. Gunasekaran, S.J. Childe, S.F. Wamba, and T. Papadopoulos. 2016. "The impact of big data on world-class sustainable manufacturing." The International Journal of Advanced Manufacturing Technology, 84(1-4): 631-645.

Dubey, R., Z. Luo, A. Gunasekaran, and M.A. Douglas. 2018. "Big Data and Predictive Analytics in Humanitarian Supply Chains: Enabling Visibility and Coordination in the Presence of Swift Trust." The International Journal of Logistics Management.

Dubey, R., and A. Gunasekaran. 2015. “Agile manufacturing: Framework and its empirical validation.” The International Journal of Advanced Manufacturing Technology, 76(9): 2147-2157.

Eisenhardt, K.M. 1989. "Building theories from case study research." Academy of Management Review, 14(4): 532-550.

Elkins, D.A., N. Huang, and J.M. Alden. 2004. "Agile manufacturing systems in the automotive industry.” International Journal of Production Economics, 91(3): 201-214.

Feitzinger, E., and H. Lee. 1997. "Mass customisation at Hewlett-Packard: The power of postponement.” Harvard Business Review, 75(1): 116-121.

Fisher, M.L. 1997. "What is the right supply chain for your product?" Harvard Business Review, MarchApril: 105-116.

Fitzgerald, B. 1995. "Mass customisation - at a profit." World Class Design to Manufacture, 2(1): 43-46. 
Gunasekaran, A., T. Papadopoulos, R. Dubey, S.F. Wamba, S.J. Childe, B. Hazen, and S. Akter. 2017. "Big data and predictive analytics for supply chain and organizational performance." Journal of Business Research, 70: 308-317.

Gunasekaran, A. 1998. "Agile manufacturing: enablers and an implementation framework." International Journal of Production Research, 36(5): 1223-1247.

Gunasekaran, A. 1999. "Agile Manufacturing: A framework for research and development." International Journal of Production Economics, 62: 87-105.

Gupta, M., and J.F. George. 2016. "Toward the development of a big data analytics capability." Information and Management, 53(8): 1049-1064.

Hoffman, E. 2017. "Big data and supply chain decisions: the impact of volume, variety and velocity properties on the bullwhip effect." International Journal of Production Research 55(17), 5108-5126

Islam, M., and A. Karim. 2011. "Manufacturing practices and performance." The International Journal of Quality and Reliability Management, 28(1): 43-61.

Jadhav, J.R., S.S. Mantha, and S.B. Rane. 2014. "Development of framework for sustainable Lean implementation: An ISM approach." Journal of Industrial Engineering International, 10 (72). doi:10.1007/s40092-014-0072-8.

Jain, S., G. Shao, and S-J Shin. 2017. "Manufacturing data analytics using a virtual

factory representation.” International Journal of Production Research 55(18): 5450-5464.

Ji-Fan Ren, S., S. F. Wamba, S. Akter, R. Dubey, and S. J. Childe 2017. "Modelling quality dynamics, business value and firm performance in a big data analytics environment." International Journal of Production Research 55(17): 5011-5026.

Ketokivi, M., and T. Choi. 2014. "Renaissance of case research as a scientific method." Journal of Operations Management, 32(5): 232-240.

Kim, K-J., and H. Ahn. 2017. "Recommender systems using cluster-indexing collaborative filtering and social data analytics." International Journal of Production Research 55(17): 5037-5049.

Lampel, J., and H. Mintzberg. 1996. "Customising customisation.” Sloan Management Review, Fall: 21 31.

Leite, M., and V. Braz. 2016. "Agile manufacturing practices for new product development: industrial case studies.” Journal of Manufacturing Technology Management, 27(4): 560-576.

Lewis, M.A. 2000. "Lean production and sustainable competitive advantage." International Journal of Operations and Production Management, 20(8): 959-978.

Ling X. 2000. "Manufacturing capability development in a changing business environment." Industrial Management and Data Systems, 100(6): 261-270.

Mason-Jones, R., B. Naylor, and D.R. Towill. 2000. "Lean, agile or leagile? Matching your supply chain to the marketplace." International Journal of Production Research, 38(17): 4061-4070.

Matthias, O., I. Fouweather, L. Gregory, and A. Vernon. 2017. "Making sense of big data - can it transform operations management?" International Journal of Operations and Production Management, 37(1): $37-55$.

Miles, M., and A. Huberman. 1994. Qualitative Data Analysis: An Expanded Sourcebook. Sage Publications. 
Nachmias, C.F, and D. Nachmias. 1992. "Research Methods in the Social Sciences," $4^{\text {th }}$ edition. London: St. Martins Press Incorporated.

Nandhakumar, M.K., N. Ghobadian., and N. O'Regan. 2011. "Generic strategies and performanceevidence from manufacturing firms." International Journal of Productivity and Performance Management, 60(3): 222-251.

Ocampo, L., and C.O. Ocampo. 2015. "A proposed sustainable manufacturing strategy framework." Verslo Sistemos ir Ekonomika; 5(1): 87-98.

Oyedijo, A. 2012. "Strategic Agility and Competitive Performance in the Nigerian Telecommunication Industry: An Empirical Investigation." American International Journal of Contemporary Research, 2(3): 227 237.

Oztekin, A. 2017. "Big Data Analytics for Creating a Marketing Strategy in Healthcare Industry." Annals of Operations Research, 1-XX (accepted).

Pagell, M., and Z. Wu. 2009. "Building a more complete theory of sustainable supply chain management using case studies of 10 exemplars." Journal of supply chain management, 45(2), 37-56.

Papadopoulos, T., A. Gunasekaran, R. Dubey, and S.F. Wamba (2017). Editorial: Big data and analytics in operations and supply chain management: practical challenges and management aspects. Production Planning and Control 28(11/12): 873-876.

Power, D.J., A.S. Sohal, and S. Rahman. 2001. "Critical success factors in agile supply chain management. An empirical study." International Journal of Physical Distribution and Logistics Management, 31(4): 247-265.

Routroy, S., P.K. Potdar, and A. Shankar. 2015. "Measurement of manufacturing agility: a case study." Measuring Business Excellence, 19(2): 1-22.

Rymaszewska, A., P. Helo, and A. Gunasekaran, 2017. "Io'T powered servitization of manufacturing - an exploratory case study.” International Journal of Production Economics 192: 92-105.

Saldaña, J., 2015. The Coding Manual for Qualitative Researchers. Sage.

Sarkis, J. 2001. "Benchmarking for agility.” Benchmarking: An International Journal, 8(2): 88-107.

Sharifi, H. and Z. Zhang. 2001. "Agile manufacturing in practice. Application of a methodology." International Journal of Operations and Production Management, 21(5/6): 772-794.

Sheridan, J. 1998. "Pushing Productivity to New Heights.” Industry Week, 43(1): 1-16.

Tan, K.H., G. Ji, C.P. Lim, and M-L Tseng. 2017. Using big data to make better decisions in the digital economy. International Journal of Production Research 55(17): 4998-5000.

Thomas, E.F. 2014. "Platform-based product design and environmental turbulence: The mediating role of strategic flexibility.” European Journal of Strategic Management, 17(1): 107-124.

Upton, D. 1995. “What Really Makes Factories Flexible.” Harvard Business Review, July: 74-84.

Vázquez-Bustelo, D., and L. Avella. 2006. "Agile manufacturing: industrial case studies in Spain." Technovation, 26(10): 1147-1161.

Vázquez-Bustelo, D., L. Avella, and E. Fernández. 2007. "Agility drivers, enablers and outcomes: Empirical test of an integrated agile manufacturing model." International Journal of Operations and Production Management, 27(12): 1303-1332. 
Vinodh, S., S.R. Devadasan, and D. Rajanayagam. 2008. "Quantification of agility: An experimentation in an Indian electronics switches manufacturing company." Journal of Engineering, Design and Technology, 6(1): 48-64.

Vinodh, S., G. Sundararaj, and S.R. Devadasan. 2009. "Total agile design system model via literature exploration." Industrial Management and Data Systems, 109(4): 570-588.

Vokurka, R.J., and G. Fliedner. 1997. "Agility: Competitive weapon of the 1990's and beyond." Production and Inventory Management Journal, 38(3): 19-24.

Vokurka, R.J., and G. Fliedner. 1998. “The journey toward agility.” Industrial Management and Data Systems, 98(4): 165-171.

Wamba, S.F., S. Akter, A. Edwards, G. Chopin, and D. Gnanzou. 2015. "How 'big data' can make big impact: Findings from a systematic review and a longitudinal case study." International Journal of Production Economics, 165: 234-246.

Wamba, S.F., A. Gunasekaran, S. Akter, S. Ji-Fan Ren, R. Dubey, and S.J. Childe. 2017. "Big data analytics and firm performance: Effects of dynamic capabilities." Journal of Business Research, 70: 356365.

Wang, G., A. Gunasekaran, E.W.T. Ngai, and T. Papadopoulos. 2016. "Big Data Business Analytics in Logistics and Supply Chain Management: Certain Investigations for Research and Applications." International Journal of Production Economics, 176: 98-110.

Wang, J., and J. Zhang. 2016. "Big data analytics for forecasting cycle time in semiconductor wafer fabrication system.” International Journal of Production Research 54 (23): 7231-7244.

Ward, P.T., J.K. McCreery, L.P. Ritzman, and D. Sharma. 1998. "Competitive priorities in operations management." Decision Sciences, 29(4): 1035-1046.

Wu, J., H, Li, Z. Lin, and K-Y Goh. 2017. How big data and analytics reshape the wearable device market - the context of e-health. International Journal of Production Research 55 (17): 5168-5182.

Yin, R.K. 1981. “The case study crisis: some answers.” Administrative Science Quarterly, 26 (1): 58-65.

Yusuf, Y.Y., E.O. Adeleye, and K. Sivayoganathan. 2003. "Volume flexibility: the agile manufacturing conundrum." Management Decision, 41(7): 613-624.

Yusuf, Y.Y., and E.O. Adeleye. 2003. "Agile Operations and Simultaneity Concept - An Introduction." The First International Conference on Performance Measures, Benchmarking and Best Practices, Guimaraes, Portugal, June 11-15.

Yusuf, Y.Y., and A. Gunasekaran. 2002. "Agile Manufacturing: A taxonomy of strategic and technological imperatives.” International Journal of Production Research, 40(6): 1359-1387.

Yusuf, Y.Y., M. Sarhadi, and A. Gunasekaran. 1999. "Agile Manufacturing: The drivers, concepts and attributes." International Journal of Production Economics, 62: 33-43.

Zhang, Y., S. Ren, Y. Liu, and S. Si. 2017. "A big data analytics architecture for cleaner manufacturing and maintenance processes of complex products." Journal of Cleaner Production, 142: 626-641.

Zhang, D.Z. 2011. "Towards theory building in agile manufacturing strategies-Case studies of an agility taxonomy." International Journal of Production Economics, 131(1): 303-312.

Zhang, Z. and H. Sharifi. 2000. "A methodology for achieving agility in manufacturing organisations." International Journal of Operations and Production Management, 20(4): 496-512. 
Zhong, R.Y., C. Xu, C. Chen, and G. O. Huang. 2017. "Big Data Analytics for Physical Internet-based intelligent manufacturing shop floors." International Journal of Production Research 55(9): 2610-2621.

Zhou, Z.H., N.V. Chawla, Y. Jin, and G.J. Williams. 2014. Big data opportunities and challenges: Discussions from data analytics perspectives [discussion forum]. IEEE Computational Intelligence Magazine, 9(4): 62-74. 